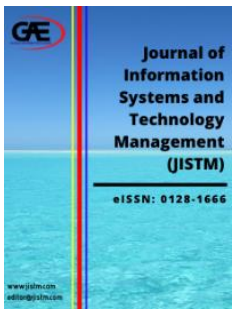

\author{
JOURNAL OF INFORMATION \\ SYSTEM AND TECHNOLOGY \\ MANAGEMENT (JISTM) \\ WWW.jistm.com
}

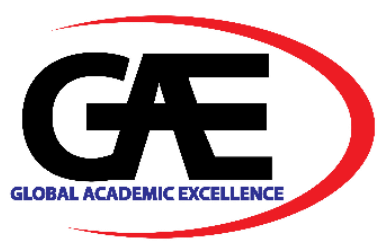

\title{
DETERMINANTS OF BEHAVIORAL INTENTION TO USE BITCOIN IN MALAYSIA
}

\author{
Farris Ian Gillies ${ }^{1}$, Chun-Teck Lye ${ }^{2}$, Lee-Ying Tay ${ }^{3^{*}}$
}

\author{
Faculty of Business, Multimedia University, Melaka, Malaysia \\ Faculty of Business, Multimedia University, Melaka, Malaysia \\ Faculty of Business, Multimedia University, Melaka, Malaysia \\ Email: lytay@mmu.edu.my \\ * Corresponding Author
}

\section{Article Info:}

\section{Article history:}

Received date: 13.07 .2020

Revised date: 10.08 .2020

Accepted date: 30.09 .2020

Published date: 01.12.2020

\section{To cite this document:}

Gillies, F. I., Lye, C. T., \& Tay, L. Y. (2020). Determinants of Behavioral Intention to Use Bitcoin in Malaysia. Journal of Information System and Technology Management, 5 (19), 2538.

DOI: $10.35631 /$ JISTM.519003.

This work is licensed under $\underline{\mathrm{CC} B Y} 4.0$ (1)

\begin{abstract}
:
Bitcoin is an emerging digital asset and is getting more attention in the media as of writing. Though, despite the regulatory matters, this paper is more concerned with the factors that influence the behavioral intention to use Bitcoin by the Malaysian. Although there are some recent studies on the intention and acceptance of Bitcoin, yet there is limited evidence from Malaysia. Therefore, this study intends on shedding some light on the current stance of the Malaysians on Bitcoin by examining the factors that affect the behavioral intention to use Bitcoin in Malaysia grounded on the Unified Theory of Acceptance and Use of Technology (UTAUT) model. The data was collected using an online self-administered questionnaire through the relevant local Malaysian forums and local cryptocurrency groups. The result shows that performance expectancy has the greatest influence on the users' behavioral intention to use Bitcoin, followed by other factors such as social influence and facilitating conditions. Additional analysis of variance and moderation analyses show no significant difference in the mean of the behavioral intention between different demographic characteristics, and the interactions of the demographic characteristics and the UTAUT factors also demonstrate an insignificant effect on the behavioral intention to use Bitcoin. The result suggests that the behavioral intention to use Bitcoin by the Malaysian may increase if the use of Bitcoin can provide convenience to the public and businesses, but it is also influenced by the social and facilitating conditions. The result well reflects the main function of Bitcoin, that is as a currency and also as an investment tool. The finding echoes the effort and policies of the government of Malaysia to find an equilibrium between the use and the abuse of digital currencies as a currency, as well as the risks and returns of digital currencies as an investment tool.
\end{abstract}




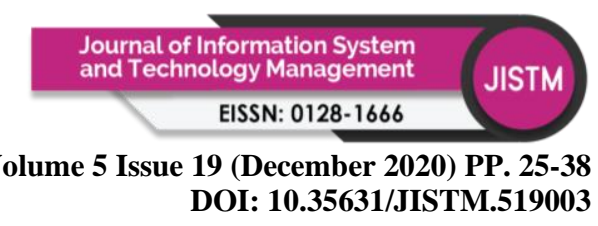

Keywords:

Behavioral Intention; Bitcoin; Blockchain; Cryptocurrency; UTAUT

\section{Introduction}

Technological progression in the information technology (IT) field and its exponential growth has fostered many things, from the creation of new products and services, innovation, to outright disruption from the status quo. This is particularly true for finance and more so with the increasing interest in Fintech. But what has been sweeping the headlines since late 2017 is the emergence of blockchain technologies such as Bitcoin that struck an all-time high of over $\$ 19,783$ from the advent of early institutional interest. Its plentiful cryptocurrency subordinates that follow behind with their own value proposition also rode the crypto-rally. Bitcoin is a digital currency that is recorded on a distributed and immutable ledger system on a decentralized network with no intermediary and is cryptographically secured on blockchain. A trust less, permission less, peer to peer system developed by a person or group with the pseudonym 'Satoshi Nakamoto'. Since 2008 and Bitcoin's inception, more and more use cases are being realized for Bitcoin, in addition to other blockchain digital assets. Numerous countries have facilitated the growth of this technology and furthermore have their central banks look into it. Though we are more concerned with Malaysia. With central bank of Malaysia, that is the Bank Negara Malaysia's stance of not accepting cryptocurrencies such as Bitcoin as a legal tender, it is still permitted with the recent guidelines for anti-money laundering and 'know your customer' requirements for exchanges who must adhere to being reporting institutions. Though, despite the regulatory matters, this paper is more concerned on the behavioral intention to use and the factors that influencing the use of Bitcoin by the Malaysian public.

Although there are some recent studies on the intention and acceptance of Bitcoin (Abraham et al., 2019; Gazali et al., 2018; Gunawan \& Novendra, 2017; Pakrou \& Amir, 2016), yet there is limited evidence from Malaysia. Therefore, this study should play an important role in determining the factors that would drive the current behavioral intention to use Bitcoin, and as the Bank Negara Malaysia is indicating a positive stance through drafting regulatory guidelines, such research would be helpful for regulatory bodies to understand the status quo of Bitcoin acceptance with users and non-users. From a managerial point of view, this research can help express the prerequisites for successful Bitcoin acceptance in various business sectors by gaining new knowledge and the behavioral intention of the existing users, potential users, and non-users of Bitcoin. And lastly, from an academic perspective, this study would contribute to the literature on the relationship between the Unified Theory of Acceptance and Use of Technology (UTAUT) model, and the realization of the digital currency. This comes from the limited academic work involved in the factors that drive consumers to adopt digital currency such as Bitcoin. While technology acceptance models have been used to better understand the actual and intended use of a new technology such as online and mobile platforms, this research will extend the scope and UTAUT model to the context of Bitcoin, which is not only an enduser technology like in other studies but also an investment instrument for investors. 


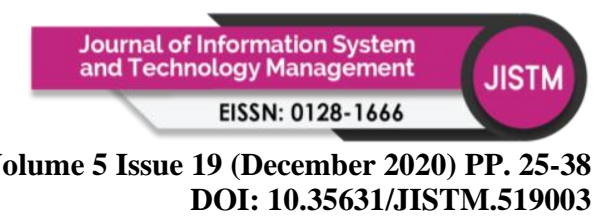

\section{Literature Review}

\section{What is Bitcoin?}

We are seeing more attention growing within the cryptocurrency space, most notably with Bitcoin. Bitcoin is a peer-to-peer currency that allows direct interaction amongst individuals, what this means is that it eliminates any need for involving a third party such as banks (Nakamoto, 2009). This is what Satoshi Nakamoto, the unknown person or group behind the pseudonym had begun through their development of Bitcoin through utilizing the technology of blockchain. By ingenious and inherent design, the blockchain, which was also incepted by Nakamoto, is an incorruptible digital ledger that is programmed to record all kinds of transactions (Tapscott \& Tapscott, 2016). From a security aspect, its decentralized nature makes it impenetrable from a single point of entry due to the existence of miners who constantly maintain the network through verifying transactions through "mining". Miners are incentivized through to release of new Bitcoin, though, the amount of Bitcoin in circulation cannot exceed 21 million Bitcoins, thus the risk of inflation is very low (Nakamoto, 2009). Its limited supply is pre-set to implement scarcity with the digital asset. Such scarcity is not possible with current fiat currency as new currency can be printed by the central banks which has controversial implications in the long run. It essentially mimics items such as precious metals which have a limited supply, and hence explains why Bitcoin is considered the "Gold of Cryptocurrency".

With regard to the technology, there are three main elements which are linked to each other the users, the blockchain, and the miners. In this current day and age, we are seeing a loss of confidence amongst people and the financial system; Bitcoin offers a new way to conduct transactions worldwide. Every payment transferred in the network is clustered in a block of transactions, called the blockchain (Böhme et al., 2015). What is so unique about the blockchain is that it prevents the issue of double spending. This means that any amount of digital money cannot be sent/spent several times to another account other than the original amount availably held. Furthermore, the chronological ordering of the blockchain presents a chain of hash values; each new block that is created contains of new transactions and additionally of a hash value from the block before (Conte de Leon et al., 2017). This shows that there is immutability and an impossibility to cheat the proof-of-work consensus algorithm. That is, unless one were to own over $50 \%$ of the miners in the system which is almost impossible. There exists an array of opportunities whereby Bitcoin can provide for both consumers and businesses. The fact that it is based on a decentralized system and purely the Bitcoin miners' who run programs based on the proof of work algorithm shows that there is no need to trust any financial institution or third party for the control of transactions. In addition, there are low transaction fees and no initial transaction costs for registering. Transferring funds is almost immediate, depending on the volume of users on the network; and ultimately it eliminates the risk of double spending (Fanning \& Centers, 2016; Nair \& Cachanosky, 2017). Another added advantage which is rather critical is Bitcoins anonymity. Which is beneficial but comes at a cost which was mentioned previously in this chapter on its usage in the digital marketplaces for illicit trading activities. Though ultimately, regulation and guidelines on its use could be a tool to mitigate (to a degree) the level of criminal activity.

\section{The Legal Status of Bitcoin in Malaysia}

There is undeniable growth in the blockchain space with Bitcoin being adopted more and more globally. The legal status of it will substantially vary from one country to another, as well as its classification as a digital asset or currency. With global progressive adoption, this study 


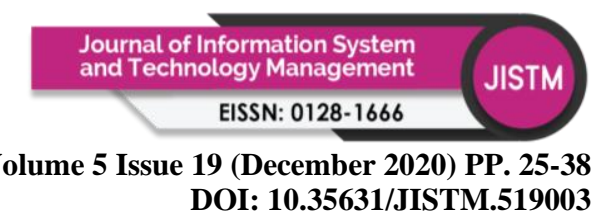

aims to aid towards the understanding of the behavioral intention to use Bitcoin in Malaysia. Firstly, we must go through its current legal status and adoption. While certain countries may explicitly allow its use and trade, others may have outright restricted or banned it. We can see the level of acceptance a country has on Bitcoin from its legal status as a starter. The top countries where Bitcoin is legal include: The United States, Canada, Australia, Europe, Japan, Israel, and Singapore. Singapore is a great example as they have begun taxing the digital asset and also obliged exchanges and ATM to the green list, following the French Bitcoin law. Now seeing the growing trends with nations and governments accepting Bitcoin, we can't help but ask what Malaysia's current legal status is before venturing towards the local consensus on its acceptance. A statement on Bitcoin by BNM on 2nd January 2014 mentioned that:

"The Bitcoin is not recognized as legal tender in Malaysia. The Central Bank does not regulate the operations of Bitcoin. The public is therefore advised to be cautious of the risks associated with the usage of such digital currency"

Such ambiguity on the sentiment shows that currently Bitcoin is legal in Malaysia, though it may not be recognized as legal tender, it is not considered as an illegal one either, nor do they prohibit the use of it. This could be attributed to the limited research and understanding of Bitcoin in Malaysia by the regulating bodies; but it is not entirely disregarded. The most that is stated is to advise citizens to be wary of the associated risks of engaging in trade and use of the digital currency. Caution is mentioned due to the fact that due to its anonymous, cryptographic and difficult to trace transactions result in many illegal activities that happen online in what is known the 'dark net'. Using special programs to access these networks, illicit trade such as purchase of illegal digital goods, drugs, assassins, terrorist funding, and more is predominantly funded by cryptocurrencies such as Bitcoin. In view that Bitcoin is pseudonymous in nature, this has raised concerns that it can be used as a tool for money laundering or as an exchange for illicit goods and services (Brito \& Castillo, 2013; Grant \& Hogan, 2015). As a result, many countries take caution into regulating cryptocurrencies as such risks are existent.

Malaysia is seen to have a permissive stance (from a legal perspective) towards the adoption of the cryptocurrency though we are seeing growing adoption of such a digital asset in our economy. There are many rather failed attempts into launching various forms of electronic currency, from negative speculation on the security, application, and reliability of payment services to other e-commerce businesses. Furthermore, there are always risks on the attacks on exchanges as well as digital wallets, government threats, and associations with crime. But it is evident that Bitcoin is still thriving despite all of these risks. This can be seen in its growth in value and market capitalization which is transparent to everybody. As its price per Bitcoin rises, businesses and users around have greater opportunity for engaging in this hugely new market. Though, despite the market infancy, it is still unknown on what the prerequisites for successful Bitcoin recognition in various other businesses should be. Such a growing area with Malaysia having an open legal framework to it is an area that is still untapped by industry participants and users within. As previously mentioned on Bitcoin's legal status in the background of the study section, BNM does not recognize Bitcoin as a legal tender, but will also not regulate the operations from a statement in 2014. Now, a very recent statement from BNM governor at the Global Symposium on Developing Financial Institutions indicates Malaysia opening its doors towards Bitcoin. This comes from their statement that they are working on cryptocurrency guidelines as quoted on the 20th September 2017: 


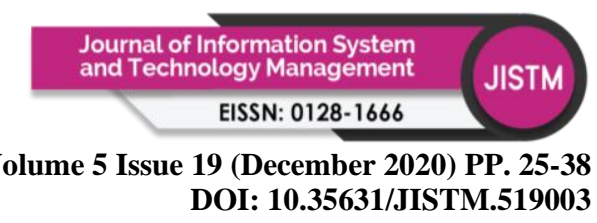

"We hope to come out with guidelines on cryptocurrencies before the end of the year: in particular, those relating to anti-money laundering and terrorist financing. We want to ensure that there are clear guidelines for those who want to participate in this sector."

Though not an explicit statement, it suggests that the government will legalize Bitcoin as a currency since they are adding guidelines and allowing citizens to participate in the cryptocurrency market legally through setting guidelines relating to anti-money laundering and terrorist financing. From such optimistic news, legalization and regulation of cryptocurrencies would open opportunities for blockchain technology to be deployed in a range of services. This in turn also would create a mass of new investment into the country, particularly into Bitcoin and other cryptocurrencies. With Malaysia drafting guidelines, further study on the behavioral intention to use Bitcoin could clear the air of ambiguity and improved understanding of the current acceptance of Bitcoin in Malaysia. Though as of currently, Bitcoin can be purchased from a number of outlets in Malaysia legally. Such outlets where any user can sign up to buy and sell Bitcoin peer to peer with the website acting as the escrow service between both parties. The prices may be much higher than what exchanges may offer. Such platforms offer relevant 'Know Your Customer' inspection to adhere to local regulations. This goes to show that as of the current date, there is growing demand for Bitcoin and markets are being established in place in Malaysia. Following that, the Bank Negara Malaysia has issued a policy document for digital currencies on February 27, 2018, to: "ensure that effective measures are in place against money laundering and terrorism financing risks associated with the use of digital currencies and to increase the transparency of digital currency activities in Malaysia." (Bank Negara Malaysia, 2018). In the most recent changes in the digital currency policy are the third revision of Guidelines on Recognized Markets on May 17, 2019, which set out the requirements for the registration of a person as a recognized market operator and its ongoing requirements, and the issuance of the first Guidelines on Digital Assets on January 15, 2020, which set out the requirements for an issuer seeking to raise funds through digital token offering and the registration of a platform operator to operate an Initial Exchange Offering platform by the Securities Commission Malaysia (Securities Commission, 2019; 2020).

\section{Methodology}

This study aims to investigate the factors affecting the behavioral intention to use Bitcoin. This will be studied through applying the UTAUT model to the case of Bitcoin (Venkatesh et al., 2003). The UTAUT model has been mostly applied to the acceptance of other technology, however, not much research has been conducted on its application to Bitcoin technology ${ }^{1}$. The application of the model will offer to identify the factors influencing the behavioral intention to use the digital currency of Bitcoin in Malaysia to aid users, businesses and academia for further research. Nevertheless, since Bitcoin, as of now is not fully recognized as legal tender in Malaysia and its usage is at the infant stage and not widespread in Malaysia, this has keep the scope of this study up to the aspect of behavioral intention only. The dependent variable being the behavioral intention to use Bitcoin, whereas the independent variables being the effort expectancy, facilitating conditions, performance expectancy and social influence which are obtained from the UTAUT model. Ultimately the main research objective of this research

\footnotetext{
${ }^{1}$ Although Venkatesh et al. (2012) has extended the UTAUT to UTAUT2 by adding three new constructs: hedonic motivation, price value, and habit, the UTAUT is more appropriate in this context, considering that bitcoin is a relatively new innovative product of new technology and it is yet widely adopted and used in the country.

Copyright $\odot$ GLOBAL ACADEMIC EXCELLENCE (M) SDN BHD - All rights reserved
} 
Volume 5 Issue 19 (December 2020) PP. 25-38 DOI: 10.35631/JISTM.519003

is to determine the factors that influence the behavioral intention to use Bitcoin in Malaysia. In addition, the relationships between the behavioral intention to use Bitcoin and the factors derived from the model may also depends on other moderating factors such as gender, age, ethnicity, education, and income level. Therefore, further tests are to be carried out to gain more insight and inferences towards what affects the behavioral intention to use Bitcoin in Malaysia.

In behavioral studies, behavioral intention is generally defined as a measure of the strength of one's intention to perform a specific behavior (Fishbein \& Ajzen, 1975). In the same vein, in technology acceptance researches, it usually refers to the willingness of individual to accept and adopt a technology system (Davis, 1989; Venkatesh et al., 2012). Accordingly, this paper uses behavioral intention to gauge the inclination of the Malaysians to use Bitcoin, as analogous to the use of technology.

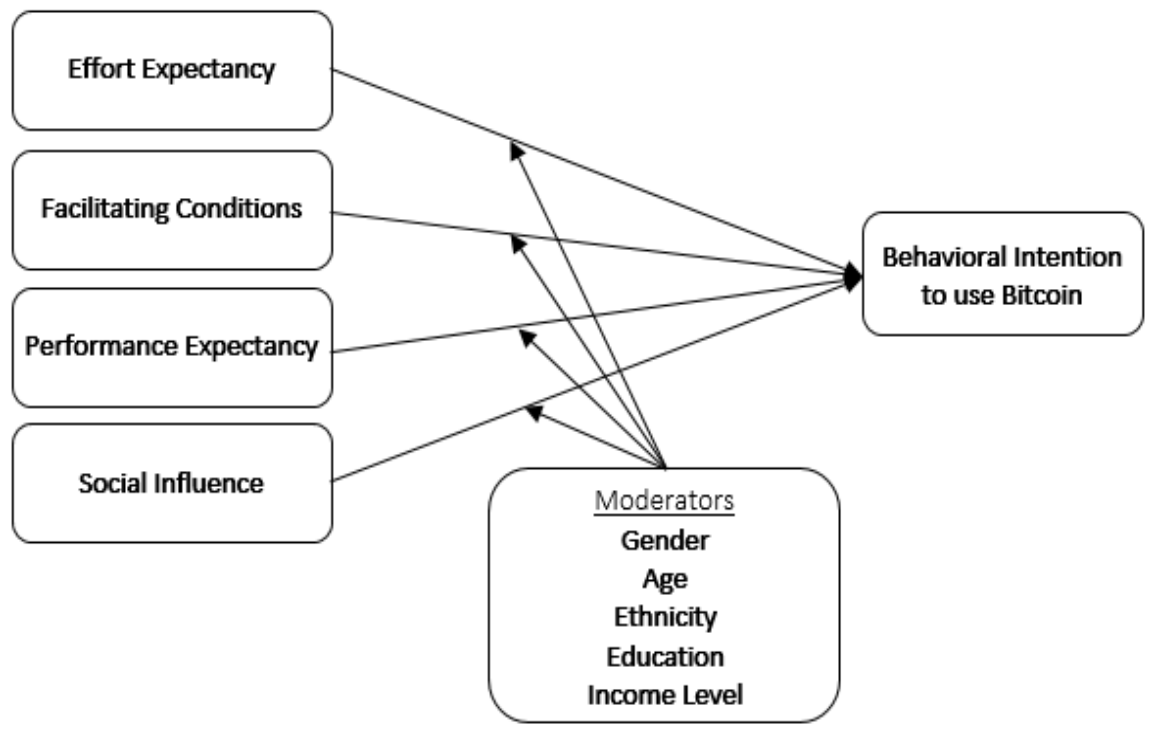

Figure 1. Conceptual Framework

Effort expectancy can be defined as: "the degree of ease associated with the use of the system" (Venkatesh et al., 2003). From prior researches, we can see that several studies support effort expectancy towards the behavioral intention or acceptance of a technology (Soomro, 2019; Permana \& Dewi, 2019). It can be seen that the degree of ease of use associated with a system has a significant impact on the acceptance on technology. One with a much higher learning curve may require much more effort and thus renders the adoption much slower than one with an easier effort. Bitcoin does require a degree of knowledge on setting up a digital wallet to hold the Bitcoin, but it only requires minimal efforts to use a wallet and engage in a transaction. Thus, this study expects there to be a positive relationship between effort expectancy and the behavioral intention to use Bitcoin in Malaysia. Facilitating conditions can be defined as: "the subjective factor that makes people feel it is easy to take action under a certain environment" (Thompson et al., 1991). The facilitating conditions involve the community of people who are engaged in the use of such technology and it can significantly affect a new-user's expectation and behavioral intention to adopt a technology. With respects to Bitcoin, several studies show 


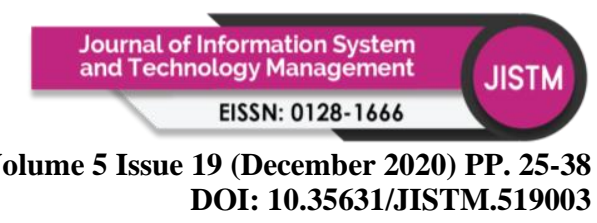

positive significance of facilitating conditions on behavioral intention. Among them are Gunawan and Novendra (2017), and Silinskyte (2014). The acceptance and intention to use Bitcoin would significantly require a positive facilitative condition. Within Malaysia this encompasses the legal framework, as well as the community of users and businesses that are engaged with the use of Bitcoin as a medium of exchange, or investment tool. We are seeing a growth in the number of businesses that accepted Bitcoin. Therefore, this study expects there to be a positive relationship between the facilitating conditions and behavioral intention to use Bitcoin in Malaysia.

Venkatesh et al. (2003) has defined performance expectancy as: "the degree to which an individual believes that using the system will help him or her to attain gains in job performance." This aspect is considerably important because users expect some form of performance expectancy when adopting such technology (Bitcoin). If Bitcoin can pose some form of improvement in ones' work, whether this involves its use as a currency or its performance as an investment vehicle, then this would have a direct effect towards its level of behavior intention. Earlier studies, such as, Alkhaldi (2017), and Khazaei (2020) have demonstrated a positive relationship between performance expectancy and behavioral intention. Its universality shows its applicability in Bitcoin, further, with one study conducted on Bitcoin, it showed that performance expectancy positively and significantly affects behavioral intention. We can visualize that Bitcoin could significantly impact different sectors through its adoption as a virtual currency in the economy ceteris paribus (towards its legal status). Due to its cryptographic, cost efficient and fast transaction speed; it can have a significant impact towards one's performance expectancy. Therefore, this study expects there to be a positive relationship between performance expectancy and the behavioral intention to use Bitcoin in Malaysia. Thompson et al. (1991) defines social influence as: "the degree to which an individual perceives that important others believe he or she should use the new system". Yu (2012) found that social influence had a significant relationship with behavioral intention towards acceptance of new technology. In a more relevant study, Khazaei (2020) also found that social influence has significant positive relationship with behavioral intention towards the adoption of blockchain technology among Malaysian SMEs. There should be a significant relationship between social influence and the acceptance of Bitcoin as more famous figures, credible persons and/or institutions begin adopting Bitcoin and cryptocurrency technology. With such a widely used and established network to partner with a Bitcoin payment service, wider adoption will result. Accordingly, this study expects there to be a positive relationship between the social influence and the behavioral intention to use Bitcoin in Malaysia.

\section{Findings and Discussion}

\section{Data}

The survey data from 200 respondents was collected using online self-administered questionnaire through the relevant local Malaysian forums and local cryptocurrency groups (Bitcoin Forums, Facebook Groups, Local Bitcoin Communities, Reddit Malaysia, etc.). The targeted population is most suitable due to the diversity in users online with or without technical knowledge or understanding of Bitcoin. As a result, the population will have both users, nonusers, and potential user's data which will relevantly suit towards the target population required for this study. The data collected were then analysed using SmartPLS (Ringle et al., 2015). 
Table 1: Demographic Information

\begin{tabular}{lll}
\hline Demographic profile & Count & \% \\
\hline Gender & & \\
Female & 49 & 24.5 \\
Male & 151 & 75.5 \\
& & \\
Age & & \\
Below 20 & 31 & 15.5 \\
$21-30$ & 122 & 61.0 \\
$31-40$ & 33 & 16.5 \\
$41-50$ & 10 & 5.0 \\
Above 50 & 4 & 2.0
\end{tabular}

Education Level

Low (< Diploma) $\quad 20 \quad 10.0$

Middle $\quad 35 \quad 17.5$

High (> Bachelor's Degree) $\quad 145 \quad 72.5$

Income Level

Low (< RM2001) $\quad 102 \quad 51.0$

Middle $\quad 54 \quad 27.0$

High (> RM4000) $\quad 44 \quad 22.0$

Ethnicity

Malay

$60 \quad 30.0$

Chinese

$102 \quad 51.0$

Indian

$20 \quad 10.0$

Others

$18 \quad 9.0$

Table 2: Descriptive Statistics

\begin{tabular}{llllll}
\hline Variable & $\begin{array}{l}\text { Instrume } \\
\text { nt }\end{array}$ & Mean & $\begin{array}{l}\text { Std. } \\
\text { Dev. }\end{array}$ & $\begin{array}{l}\text { Excess } \\
\text { Kurtosis }\end{array}$ & Skewness \\
\hline Behavioral Intention (BI) & BI_1 & 3.255 & 1.342 & -1.127 & -0.312 \\
& BI_2 & 3.590 & 1.429 & -0.993 & -0.618 \\
& BI_3 & 3.240 & 1.266 & -0.936 & -0.207 \\
& BI_4 & 3.205 & 1.332 & -1.151 & -0.125 \\
\cline { 2 - 6 } Effort Expectancy (EE) & EE_1 & 3.200 & 1.158 & -0.785 & -0.261 \\
& EE_2 & 3.445 & 1.248 & -0.766 & -0.473 \\
Facilitating Conditions (FC) & EE_3 & 3.565 & 1.283 & -0.568 & -0.704 \\
\cline { 2 - 6 } & FC_1 & 3.710 & 1.173 & -0.406 & -0.692 \\
Performance Expectancy & 3.575 & 1.116 & -0.435 & -0.538 \\
(PE) & FC_3 & 2.910 & 1.154 & -0.698 & 0.158 \\
\cline { 2 - 6 } & PE_1 & 3.585 & 1.305 & -0.802 & -0.568 \\
Social Influence (SI) & PE_2 & 3.220 & 1.250 & -0.949 & -0.207 \\
\cline { 2 - 5 } PE_3 & 3.050 & 1.272 & -1.025 & -0.050 \\
\hline
\end{tabular}




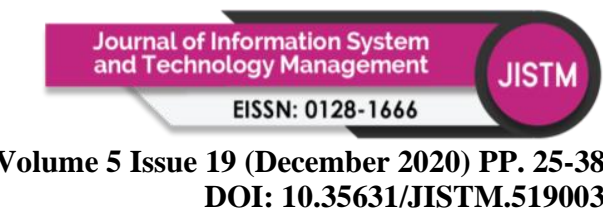

\begin{tabular}{lllll} 
SI_2 & 3.160 & 1.298 & -1.037 & -0.149 \\
SI_3 & 3.195 & 1.260 & -0.869 & -0.313 \\
SI_4 & 3.600 & 1.158 & -0.536 & -0.557 \\
SI_5 & 3.560 & 1.152 & -0.494 & -0.563 \\
\hline
\end{tabular}

The demographic information of the respondents and the descriptive statistics of the instruments are reported in Table I and Table II respectively. From Table I, among all the 200 respondents, $24.5 \%$ (49) are female and $75.5 \%$ (151) are male. The demographic information also shows that majority of the respondents have age between 21-30 years old $(61.0 \%)$, followed by age between $31-40(16.5 \%)$ years old. This particular group of respondents (2140 years old), who were born between 1978 to 1997 and are frequently categorized as Generation Y or Millennials, are known as technology savvy and sophisticated (Bolton et al., 2013). Most of the respondents (72.5\%) are either undergraduates, graduates or postgraduates. Moreover, the data shows that nearly half $(49 \%)$ of the respondents earn no less than RM2001 per month and $22 \%$ of the respondents earn monthly wages of RM4000 or more. The respondents comprise of four main groups of ethnicities, in which $51 \%$ are Chinese, $30 \%$ are Malays, $10 \%$ are Indians and $9 \%$ are others. The descriptive statistics of the research instruments using 5-point Likert scale from 1 (strongly disagree) to 5 (strongly agree) are reported in Table II. The overall mean point of the behavioral intention, effort expectancy, facilitating conditions, performance expectancy and social influence is 3.323, 3.403, 3.398, 3.285 and 3.262 respectively. The overall statistics also shows that there is no serious violation of the normality assumption as the excess kurtosis and the skewness of the data generally fall between the range of \pm 1 (Hair et al., 2017).

\section{Internal Consistency and Validity of the Model}

The results of the tests on the internal consistency of the measurement model is presented in Table III. The Cronbach's Alpha of the reflective variables are all more than the minimum threshold value of 0.700 with the lowest value of 0.702 given by the facilitating conditions and the highest value of 0.834 reported by the effort expectancy. Likewise, all the rho_A reported are also higher than the 0.700 threshold with the lowest $(0.735)$ and the highest $(0.851)$ rho_A given by the facilitating conditions and effort expectancy respectively. Additionally, all the values of the composite reliability of the variables are also greater than 0.700 . These results collectively validate the internal consistency of the model. The values of the average variance extracted (AVE), range from 0.500 to 0.748 , exceed the threshold value of 0.500 in which the instruments as a whole have explain at least $50.0 \%$ to $74.8 \%$ of the constructs. This lends support to the convergent validity of the instruments (Hair et al., 2014). The Fornell-Larcker criterion (Fornell \& Larcker, 2014) and the heterotrait-monotrait (HTMT) ratio (Henseler et al., 2015), as reported in Table IV, were referred when assessing the model's discriminant validity. Overall, the results show that the discriminant validity of the constructs has been established with HTMT ratio generally lower than 0.900, and the Fornell-Larcker criterion is reached as the value of the square root of the AVE of each construct is higher than the correlations with other latent constructs. The inner variance inflation factor (VIF) of the variables reported in Table $\mathrm{V}$ are all less than 3.000. This indicates that there is no multicollinearity issue in the model. 
Table 3: Internal Consistency of the Model

\begin{tabular}{lllll}
\hline & $\begin{array}{l}\text { Cronbach's } \\
\text { Alpha }\end{array}$ & rho_A & $\begin{array}{l}\text { Composite } \\
\text { Reliability }\end{array}$ & AVE \\
\hline Behavioral Intention & 0.770 & 0.781 & 0.853 & 0.594 \\
Effort Expectancy & 0.834 & 0.851 & 0.899 & 0.748 \\
Facilitating Conditions & 0.702 & 0.735 & 0.836 & 0.632 \\
Performance & 0.824 & 0.833 & 0.895 & 0.739 \\
Expectancy & 0.745 & 0.754 & 0.831 & 0.500 \\
Social Influence & & & &
\end{tabular}

Table 4: Fornell-Larcker Criterion and Heterotrait-Monotrait Ratio

\begin{tabular}{|c|c|c|c|c|c|}
\hline & BI & EE & FC & PE & SI \\
\hline BI & 0.770 & & & & \\
\hline $\mathrm{EE}$ & $0.649(0.794)$ & 0.865 & & & \\
\hline FC & $0.613(0.830)$ & $0.615(0.792)$ & 0.795 & & \\
\hline PE & $0.740(0.919)$ & $0.752(0.885)$ & $0.568(0.735)$ & 0.860 & \\
\hline SI & $0.666(0.860)$ & $0.628(0.775)$ & $0.593(0.785)$ & $0.610(0.763)$ & 0.707 \\
\hline
\end{tabular}

Table 5: Variance Inflation Factor (VIF)

\begin{tabular}{ll}
\hline $\begin{array}{l}\text { Dependent variable: Behavioral } \\
\text { Intention }\end{array}$ & VIF \\
\hline Effort Expectancy & 2.753 \\
Facilitating Conditions & 1.843 \\
Performance Expectancy & 2.522 \\
Social Influence & 1.953 \\
\hline
\end{tabular}

\section{Bootstrapping Analysis}

The parameters of the model, as presented in Table VI, are estimated using bootstrapping approach with 1000 iterations. The value of the standardized root mean square residual for model fit test has a value of 0.094 and it is less than the threshold of 0.100 , which indicates that the appropriateness of the model (Henseler et al., 2015). The value of the R-square is 0.642 is above the minimum substantial threshold of 0.640 (Chin, 1998). The result of the bootstrapping analysis not only show that all the variables have positive relationship with the behavioral intention, the facilitating conditions, performance expectancy and social influence also have statistically significantly influenced on the behavioral intention to use Bitcoin in Malaysia. 
Table 6: Bootstrapping Analysis

\begin{tabular}{llccc}
\hline $\begin{array}{l}\text { Dependent variable: Behavioral } \\
\text { Intention }\end{array}$ & Coefficient & Std.Dev. & $\boldsymbol{t}$ stat. & $\boldsymbol{p}$-value \\
\hline Effort Expectancy & 0.032 & 0.083 & 0.393 & 0.694 \\
Facilitating Conditions & $0.179 * * *$ & 0.064 & 2.790 & 0.005 \\
Performance Expectancy & $0.453^{* * *}$ & 0.077 & 5.883 & 0.000 \\
Social Influence & $0.263^{* * *}$ & 0.065 & 4.044 & 0.000 \\
\hline Note: *** indicates the 1\% significance level. The p-values are estimated using bootstrapping \\
(1000 iterations). The standardized root mean square residual is 0.094. The $R$-square is 0.642.
\end{tabular}

Although the result shows that the effort expectancy does have some positive impact on the behavioral intention to use Bitcoin, but yet the effect is found to be insignificant. This perhaps is due to the limited transaction of Bitcoin as most of the owners of Bitcoin consider it as a form of mid-term 'investment' (Tapscott \& Tapscott, 2016). On the other hand, facilitating conditions, performance expectancy and social influence showed positive significance relationships with behavioral intention to use Bitcoin. In such an environment like Malaysia with supportive online mediums such as Facebook groups and Reddit forums, it's no doubt that information to facilitate the ease to learn and use such a technology exists. Gunawan and Novendra (2017) who conducted an analysis of technology acceptance and customer trust in Bitcoin in Indonesia also found that facilitating conditions has a positive effect on use behavior. Though performance expectancy was shown to be related to job performance, but in this case not only for jobs but for tasks such as its expected performance as a currency, or as an investment tool. Therefore, an owner might think that he/she will ultimately be benefited by considering Bitcoin as an alternative tool for trading and/or for investment. This could also justify why it has the greatest effect on the behavioral intention. Likewise, social influence also demonstrates significant effect when relating to the behavioral intention of using Bitcoin. This is in line with the view that social factors such as the subjective norm and image are things that can sway others significantly (Thompson et al., 1991).

\section{Additional Analyses}

This study also performs analysis of variance on the behavioral intention to use Bitcoin by age, gender, education, income level and ethnicity. The result shown in Table VII indicates that there is no significance difference in the mean of the behavioral intention of respondents between different ages, genders, education levels, income levels and ethnicity. This implies that different demographic characteristics considered in this study have no impact on the behavioral intention. Additionally, considering that UTAUT hypothesizes that gender, age, and experience have moderating effects on technology acceptance (Chang, 2012), another analysis on the potential moderation of these demographic characteristics using the product indicator approach of smartPLS3.0, in which considers all possible pair combinations of the product terms of the latent moderators and predictors (Ramayah et al. 2018). The result, as shown in Table VIII, also reveals that such characteristics, interacting with effort expectancy, facilitating conditions, performance expectancy and social influence, do not have any significant effect on the behavioral intention to use Bitcoin in Malaysia. 
Volume 5 Issue 19 (December 2020) PP. 25-38 DOI: 10.35631/JISTM.519003

Table 7: Analysis of Variance

\begin{tabular}{lll}
\hline Variable & $\boldsymbol{F}$ statistics & $\boldsymbol{p}$-value \\
\hline Age & 1.2081 & 0.3087 \\
Gender & 1.8611 & 0.1740 \\
Education & 0.9367 & 0.3936 \\
Income & 0.6909 & 0.5024 \\
Ethnicity & 1.8774 & 0.1347 \\
\hline
\end{tabular}

Table 8: Moderation Analyses

\begin{tabular}{llllll}
\hline $\boldsymbol{B I}$ & Age & Gender & Education & Income & Ethnicity \\
\hline$E E$ & 0.012 & 0.038 & 0.047 & 0.026 & 0.005 \\
$F C$ & $0.181^{* * *}$ & $0.178^{* * *}$ & $0.145^{* * *}$ & $0.188^{* * *}$ & $0.173^{* * *}$ \\
$P E$ & $0.456^{* * *}$ & $0.459^{* * *}$ & $0.472^{* * *}$ & $0.439^{* * *}$ & $0.493^{* * *}$ \\
$S I$ & $0.274^{* * *}$ & $0.246^{* * *}$ & $0.256^{* * *}$ & $0.272^{* * *}$ & $0.264^{* * *}$ \\
$M O D$ & -0.061 & 0.035 & -0.005 & -0.004 & -0.057 \\
$M O D \times E E$ & -0.025 & -0.069 & 0.161 & -0.076 & -0.113 \\
$M O D \times F C$ & -0.039 & 0.011 & -0.107 & -0.011 & 0.074 \\
$M O D \times P E$ & 0.173 & -0.046 & -0.069 & 0.099 & -0.118 \\
$M O D \times S I$ & -0.082 & 0.087 & 0.037 & -0.011 & 0.142 \\
\hline
\end{tabular}

Note: The dependent variable is the Behavioral Intention (BI). MOD denotes the potential moderators i.e. Age, Gender, Education, Income and Ethnicity considered in the study. *** indicates the 1\% significance level. The p-values were estimated using boostrapping (1000 iterations).

\section{Conclusion}

This study is to contribute to the academia on a new asset class, the Bitcoin, which was brought to the forefront as the technology advanced. The overall result shows that performance expectancy has the greatest influence on the users' behavioral intention to use Bitcoin. This is followed by other factors such as the social influence and facilitating conditions. The result suggests that the behavioral intention to use Bitcoin by the Malaysian may be increased if the use of Bitcoin can provide convenience to the public and businesses in Malaysia. Additionally, intention to adopt Bitcoin would increase if it has high potential growth, as one of the investment tools, that could deliver attractive returns of investment, regardless of risk, to the investors. Besides, the aspect of social influence and facilitating conditions should be taken into consideration too. As more and more people and businesses adopt Bitcoin, there will be more supportive means that facilitate the use of Bitcoin, and vice versa, in turns, the behavioral intention to use Bitcoin would increase as well. The result well reflects the main function of Bitcoin, that is as a currency and also as an investment tool. The finding echoes the effort and policies of the government of Malaysia to find equilibrium between the use and the abuse of digital currencies as a currency, as well as the risks and returns of digital currencies as an investment tool (Bank Negara Malaysia, 2018; Securities Commission, 2019; 2020). The extra analysis of variance and moderation analyses conducted show that there is no significant difference in the mean of the behavioral intention to use Bitcoin between different demographic characteristics, and the interactions of the demographic characteristics and the UTAUT factors do not have any significant effect on the behavioral intention to use Bitcoin in Malaysia. On one hand, this study aims to focus on a new innovation product in technology, that is the Bitcoin, but on the other hand, this also limits the use of the complete UTAUT model, which includes the 'Use Behavior', as well as other more recent technological acceptance models. Copyright (C) GLOBAL ACADEMIC EXCELLENCE (M) SDN BHD - All rights reserved 


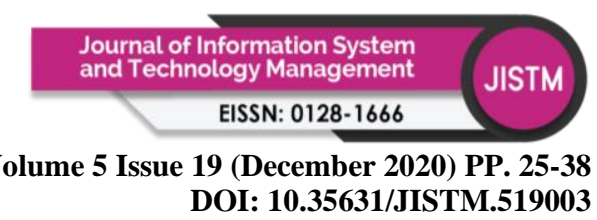

Perhaps, future research could revisit the topic once the Bitcoin or other cryptocurrencies become widely circulated.

\section{References}

Abraham, J., Sutiksno, D. U., Kurniasih, N., \& Warokka, A. (2019). Acceptance and penetration of bitcoin: The role of psychological distance and national culture. SAGE Open, July 2019, 1-14.

Alkhaldi, A. N. (2017). An empirical examination of customers' mobile phone experience and awareness of mobile banking services in mobile banking in Saudi Arabia. Interdisciplinary Journal of Information Knowledge and Management, 12(1), 283-308.

Bank Negara Malaysia (2018). Bank Negara Malaysia issues policy document for digital currencies.

Böhme, R., Christin, N., Edelman, B., \& Moore, T. (2015). Bitcoin: Economics, technology, and governance. Journal of Economic Perspectives, 29(2), 213-238.

Bolton, R. N., Parasuraman, A., Hoefnagels, A. Migchels, N., Kabadayi, S., Gruber, T., Loureiro, Y. K., \& Solnet, D. (2013). Understanding generation Y and their use of social media: A review and research agenda. Journal of Service Management, 24(3), 245-267.

Brito, J., \& Castillo, A. (2013). Bitcoin: A primer for policymakers. Arlington, Virginia: Mercatus Center.

Chang, A. (2012). UTAUT and UTAUT2: A review and agenda for future research. Journal The WINNERS, 13(2), 106-114.

Chin, W. W. (1998). The partial least squares approach for structural equation modelling. In G. A. Marcoulides (ed.), Quantitative Methodology Series: Modern Methods for Business Research (pp. 295-336). Mahwah, New Jersey: Lawrence Erlbaum Associates.

Conte de Leon, D., Stalick, A. Q., Jillepalli, A. A., Haney, M. A., \& Sheldon, F. T. (2017). Blockchain: Properties and misconceptions. Asia Pacific Journal of Innovation and Entrepreneurship, 11(3), 28-300.

Davis, F. D. (1989). Perceived usefulness, perceived ease of use, and user acceptance of information technology. MIS Quarterly, 13(3), 319-340.

Fanning, K., \& Centers, D. P. (2016). Blockchain and its coming impact on financial services. Journal of Corporate Accounting \& Finance, 27(5), 53-57.

Fishbein, M., \& Ajzen, I. (1975). Belief, attitude, intention, and behavior: An introduction to theory and research. Boston, MA: Addison-Wesley.

Fornell, C., \& Larcker, D. (2014). Evaluating structural equation models with unobservable variables and measurement error. Journal of Marketing Research, 18(3), 39-50.

Gazali, H. M., Che Ismail, C. M. H., \& Amboala, T. (2018, July 23-25). Exploring the Intention to Invest in Cryptocurrency: The Case of Bitcoin. [Paper presentation]. International Conference on Information and Communication Technology for the Muslim World, Kuala Lumpur.

Grant, G., \& Hogan, R. (2015). Bitcoin: Risks and controls. Journal of Corporate Accounting \& Finance, 26(5), 29-35.

Gunawan, F. E., \& Novendra, R. (2017). An analysis of bitcoin acceptance in Indonesia. ComTech: Computer, Mathematics and Engineering Applications, 8(4), 241-247.

Hair Jr, J. F., Sarstedt, M., Hopkins, L., \& Kuppelwieser, V. G. (2014). Partial least squares structural equation modeling (PLS-SEM): An emerging tool in business research. European Business Review, 26(2), 106-121. 


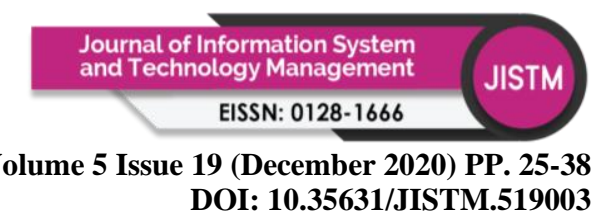

Hair, J. F., Hult, G. T. M., Ringle, C. M., \& Sarstedt, M. (2017). A Primer on Partial Least Squares Structural Equation Modeling (PLS-SEM). Thousand Oaks, CA: Sage.

Henseler, J., Ringle, C. M., \& Sarstedt, M. (2015). A new criterion for assessing discriminant validity in variance-based structural equation modeling. Journal of the Academy of Marketing Science, 43 (1), 115-135.

Khazaei, H. (2020). Integrating cognitive antecedents to UTAUT model to explain adoption of blockchain technology among Malaysian SMEs. International Journal on Informatics Visualization, 4(2), 85-90.

Nair, M., \& Cachanosky, N. (2017). Bitcoin and entrepreneurship: Breaking the network effect. The Review of Austrian Economics, 30(3), 263-275.

Nakamoto, S. (2009). Bitcoin: A peer-to-peer electronic cash system. Bitcoin.org. Retrieved from http://www.bitcoin.org/bitcoin.pdf.

Pakrou, M, \& Amir, K. (2016). The relationship between perceived value and the intention of using bitcoin. Journal of Internet Banking and Commerce, 21(2), 1-18.

Permana, G. P. L. \& Dewi, L. P. K. (2019). Analysis of acceptance and use of OVO applications using unified theory of acceptance and use of technology in Denpasar city. Jurnal Ilmiah Akuntansi dan Bisnis, 4(2), 186-203.

Ramayah, T., Cheah, J., Chuah, F., Ting, H., \& Memon, M. A. (2018). Partial least squares structural equation modeling (PLS-SEM) using smartPLS 3.0: An updated and practical guide to statistical analysis (2nd ed.). Kuala Lumpur, Malaysia: Pearson.

Ringle, C. M., Wende, S., \& Becker, J. M. (2015). SmartPLS 3. Boenningstedt, SchleswigHolstein: SmartPLS GmbH. Retrieved from http://www.smartpls.com

Securities Commission (2019). Guidelines on Recognized Markets. Retrieved from https://www.sc.com.my/api/documentms/download.ashx?id=eb8f1b04-d744-4f9aa6b6-ff8f6fee8701

Securities Commission (2020). Guidelines on Digital Assets. Retrieved from https://www.sc.com.my/api/documentms/download.ashx?id=dabaa83c-c2e8-40c39d8f-1ce3cabe598a

Silinskyte, J. (2014). Understanding bitcoin adoption: Unified theory of acceptance and use of technology (UTAUT) application. (Master's thesis). Leiden University, Leiden, The Netherlands.

Soomro, Y. A. (2019). Understanding the adoption of SADAD E-payments: UTAUT combined with religiosity as moderator. International Journal of E-Business Research, 15(1), 55-74.

Tapscott, D., \& Tapscott, A. (2016). Blockchain Revolution: How the Technology Behind Bitcoin is Changing Money, Business, and the World. Broadway, New York: Penguin Publishing Group.

Teo, T. S. H., Srivastava, S. C., \& Jiang, L. (2008). Trust and electronic government success: an empirical study. Journal of Management Information Systems, 25(3), 99-132.

Thompson, R. L., Higgins, C. A., \& Howell, J. M. (1991). Personal computing: Toward a conceptual model of utilization. MIS Quarterly, 15(1), 124-143.

Venkatesh, V., Morris, M. G., Davis, G. B., \& Davis, F. D. (2003). User acceptance of information technology: Toward a unified view. MIS Quarterly, 27(3), 425-478.

Venkatesh, V., Thong, J. Y. L., \& Xu, X. (2012). Consumer acceptance and use of information technology: Extending the unified theory of acceptance and use of technology. MIS Quarterly, 36(1), 157-178.

Yu, C. S. (2012). Factors affecting individuals to adopt mobile banking: Empirical evidence from the UTAUT model. Journal of Electronic Commerce Research, 13(2), 104-121. 